\title{
HACIA LA ELIMINACIÓN DE INEQUIDADES EN EL SISTEMA TRIBUTARIO: PROPUESTAS PARA UNA REFORMA TRIBUTARIA INTEGRAL CON EQUIDAD
}

\author{
“TOWARDS THE ELIMINATION OF INEQUITIES IN THE TAX SYSTEM: \\ PROPOSALS FOR TAX REFORM INTEGRAL WITH EQUITY"
}

\author{
Adolfo Valencia Gutiérrez ${ }^{*}$ \\ Docente Auxiliar de la Facultad de Ciencias Contables- UNMSM
}

[Recepción: Abril de 2009 / Conformidad: Mayo de 2009]

\section{RESUMEN}

La tributación es la acción con que el ciudadano entrega al Estado cierta cantidad de dinero para el financiamiento de las funciones y servicios públicos; la tributación no es un fin en sí mismo: es una herramienta de la política económica; es decir, de las directrices con que el gobierno orienta la producción y distribución de la riqueza en un país. No existe una legitimación ni credibilidad en el sistema tributario en la medida que, por el lado del pago de impuestos, se perciben altos grados de inequidad horizontal y opacidad de los mecanismos implementados y, por el lado del destino de los recursos, no se percibe una adecuada atención a las necesidades de la población, tanto en términos de cobertura como de calidad. Es pertinente bosquejar propuestas para mejorar el sistema tributario nacional y propugnar una verdadera reforma tributaria integral con equidad, porque lo que se viene haciendo desde hace mucho tiempo tiende a entenderse que tiene solamente un objetivo: la profiscalidad de los tributos, es decir, solamente tiene fines recaudatorios que muchas veces devienen en injustas convirtiéndose en un obstáculo para el desarrollo de nuestro país.

Palabras clave: Tributación, política económica, inequidad horizontal, reforma tributaria, equidad.

\begin{abstract}
Taxation is the action with which the citizens surrendered to the State a certain amount of money in financing its public functions and services, taxation is not an end in itself: it is a tool of economic policy or guidelines that the government directed the production and distribution of wealth in a country. There is no legitimacy or credibility to the tax system in that side of paying taxes, perceived high levels of horizontal inequality and opacity of the mechanisms implemented and on the side of the destination of resources, is not seen adequate attention to the months of the population, both in terms of coverage and quality.

It is desirable to design proposals to improve the national tax system and advocate a comprehensive tax reform with real equity because, as it has for a long time tends to understand that has only one objective: pro fiscalidad of taxes; in other words, Finnish only has revenue that often cause injustices that are obstacles to the development of our country
\end{abstract}

Keywords: Economic policy, taxation and tax reform, equity.

* Doctorando en Ciencias de la Educación. E- mail: avgvalencia@hotmail.com 


\section{INTRODUCCIÓN}

"La tributación es la acción con que el ciudadano entrega al Estado cierta cantidad de dinero para el financiamiento de las funciones y servicios públicos. La tributación es un aporte del contribuyente en aras del bien común. Quien no percibe el bien común está incapacitado para aceptar la tributación.

El abismo social y el desbalance regional expresan y sintetizan los problemas que afectan a la sociedad y a la economía peruana, desde el inicio de la República hasta nuestros días. La tributación no es un fin en sí mismo: es una herramienta de la política económica; es decir, de las directrices con que el gobierno orienta la producción y distribución de la riqueza en un país.

En materia tributaria en el Perú, desde hace mucho tiempo, se ha sabido qué es lo que hay que hacer, entonces es fácil colegir que en la causa del problema peruano hay una fuerza oscura que malévolamente impide que las decisiones razonables y las medidas correctas puedan ver la luz del día.

La situación de pobreza que afecta a más del 50 por ciento de la población es, en consecuencia, el ineludible desafío nacional. De ahí que surge la elemental interrogante: ¿Cómo avanzar de la pobreza al crecimiento sostenible?

La visión de futuro del Perú - tema de frecuente alusión - está indisolublemente ligada al diagnóstico del presente, en el cual se hallarán los obstáculos y hechos absurdos que tienen sus orígenes en el pasado iAcaso el perverso ciclo subdesarrollante peruano es una penosa realidad protegida por una niebla impenetrable? ¿Es posible encontrar una salida? "Extractos de la Conferencia Magistral: Manuel Estela Benavides en marzo del 2002."

Creemos firmemente que todo es posible para el que cree, por eso compartimos es- tas propuestas para el cambio, porque como peruanos tenemos la visión de un futuro mejor, cumplamos nuestra misión y hagámoslo todo con pasión.

\section{ANTECEDEDENTES}

En este sentido, trataremos de analizar dentro del marco conceptual, los aspectos fundamentales del Estado a fin de proponer las delimitaciones y establecer su real responsabilidad directa como consecuencia de sus actividades que le son inherentes.

En primer lugar, explicaremos los principios y características del sistema tributario, de modo tal que el estudio de nuestra legislación y de las legislaciones comparadas, surjan nuevos análisis que permitan profundizar y aportar ideas para su perfeccionamiento. Por ello, haré un comentario de las principales características del sistema tributario, la política económica, técnica fiscal y administración fiscal.

En segundo lugar, después de explicar lo referente al sistema tributario, trataré en especial las inequidades del sistema tributario vigente. En efecto, a partir de la normatividad engorrosa vigente han surgido nuevas modalidades de cambio a la informalidad de los ya formalizados por las excesivas cargas tributarias y sobre todo por la imperante aplicación de los aspectos formales en detrimento de los aspectos sustanciales.

Con ello, considero que se tendrá un panorama de cómo está regulado el sistema tributario y cuáles son las principales inequidades y de qué manera se legisla en detrimento de los contribuyentes, sin perjuicio de la necesaria profundización de cada uno de los temas tratados o del análisis crítico o valorativo de tales disposiciones que bien pueden ser objeto de trabajos posteriores. 
Finalmente, es pertinente bosquejar propuestas para mejorar el sistema tributario nacional y propugnar una verdadera reforma tributaria integral con equidad, porque lo que se viene haciendo desde hace mucho tiempo tiende a entenderse que tiene solamente un objetivo: la profiscalidad de los tributos, es decir, solamente tiene fines recaudatorios que muchas veces devienen en injustas convirtiéndose en un obstáculo para el desarrollo de nuestro país.

\section{INTERROGANTES PARA EL DESARROLLO DEL TEMA:}

1. ¿El sistema tributario vigente considera todos los principios tributarios que taxativamente indica la Constitución Política: de reserva de la ley, de igualdad, respeto de los derechos fundamentales de la persona y la no confiscatoriedad?

2. ¿La legislación tributaria vigente fomenta la creación de nuevas empresas o es lo contrario, los ahuyenta con las excesivas cargas fiscales y formalidades exigidas que van en detrimento de los contribuyentes?

3. ¿La prevalencia de los aspectos formales sobre los aspectos sustanciales no son motivo acaso para que muchos formales, por la onerosidad de los mismos tengan que cerrar el negocio?

4. ¿El Estado realmente tiene interés que las micro empresas, pequeñas y medianas empresas se formalicen y consoliden, sabiendo que constituyen aproximadamente el $90 \%$ de las empresas en el país?

5. ¿Es consciente el Estado de que las medidas administrativas con un sinnúmero de formalidades confunden y le generan sobrecostos a los contribuyentes, por lo cual muchos formales se reconvierten en informales?

6. ¿El traslado de la responsabilidad para recaudar tributos ajenos, constituyen una "delegación de facultades" onerosas no sólo financieras sino también repercuten en la tranquilidad sicológica del contribuyente?

7. ¿Es equitativa o justa la aplicación de los regímenes de retenciones, percepciones, detracciones y estas últimas que muchas veces por la comisión de una formalidad devienen en Sustracciones al transferir los fondos al Tesoro Público y por el cual el contribuyente ya no puede solicitar la devolución de los fondos constituidos a su nombre, por cobros adelantados sobre el precio de venta y no realmente sobre el IGV?

\section{CONCEPTO GENERAL DEL ESTADO}

El Estado surge como resultado de un largo proceso de evolución de la convivencia humana. Evidentemente el hombre desde que empieza a vivir en comunidad siente que se torna indispensable el establecimiento de un "orden" que le permite asegurar su existencia.

Es la etapa del surgimiento de las primeras estructuras asociativas. Se consolida la familia, dando paso a organizaciones superiores como la tribu, el clan, la polis y, en ese orden, como consecuencia precisamente de esa interacción humana, el Estado.

El Estado deviene así en una organización con ciertos presupuestos. Con él, se alcanza el grado más alto de la organización social, el de una unidad colectiva dotada de capacidad para la autodeterminación y regida por una ordenación jurídica. ${ }^{1}$

1 
La organización del hombre en sociedad conformada a lo largo de su historia para hacer posible su realización plena, origina necesidades diferente de las privadas o individuales que bien podríamos designar como "colectivas", desde el punto de vista del destinatario individual o social de su satisfacción. Este tipo de necesidades ha de satisfacerlas el Estado, pero no constituye su único ni exclusivo campo de acción. Porque, en mayor o menor grado y según las ideologías imperantes, puede ser a su cargo la función de suplir o complementar la órbita de acción de lo que suele llamarse el "sector privado". Del mismo modo, es posible que los particulares se encarguen de suministrar bienes meritorios $y$, en general, satisfacer necesidades en beneficio de la colectividad.

Para el cumplimiento de tales fines son necesarios recursos que permitan una acción eficaz e ininterrumpida. Más también es posible que la percepción de recursos por el Estado no tenga como objetivo primordial la obtención de medios financieros sino la regulación en materia económica, política y social, de tal forma que su captación sea consecuencia del cumplimiento de esa finalidad principal. ${ }^{2}$

El concepto clásico de la ciencia de las finanzas y ciencia fiscal indica: "La ciencia de las finanzas y ciencia fiscal es el conjunto de reglas y principios que determinan la manera de constituir, administrar e invertir el patrimonio público. En la constitución del patrimonio público, la ciencia fiscal estudia la manera de formarlo, analizando detalladamente las distintas fuentes de ingresos que componen el tesoro o el erario, así de aquellos que emanan de la comunidad misma, como de los que provienen del tesoro de los particulares. En la administración del expresado patrimonio, la ciencia fiscal estudia la

2 organización que debe darse al manejo y recaudación de los dineros públicos, señalando las normas para que aquellas funciones se desempeñen con la mayor eficacia, equidad y economía. Y por último, en la inversión de los fondos públicos, dicha ciencia establece los principios fundamentales de los gastos comunes, a fin de que aquellos se decreten y se realicen en forma tal y en cuantía tal que correspondan debidamente a la satisfacción de las necesidades colectivas dentro de las necesidades económicas de la respectiva entidad política”.

\section{CARACTERÍSTICAS DE SISTEMAS TRIBUTARIOS}

La expresión "sistema" sugiere un conjunto coordinado e interdependiente de partes que conforman un todo cuyos lineamientos generales dan sentido a cada uno de sus componentes. En materia fiscal, la doctrina alude al "sistema" para referirse a un conjunto de tributos que responde a una serie de características, fundamentos y objetivos comunes al todo y a las partes.

Según Tarantino: “cuando las reglas se imponen, o se siguen, sin orden y sin investigación de causa, con el solo propósito de lograr más fondos, se está en presencia de un régimen y no de un sistema tributario."

El Estado para el cumplimiento de su finalidad esencial, que es el bien común, requiere contar con los recursos económicos necesarios que le permitan financiar sus actividades. Parte significativa de tales recursos está integrada por los "ingresos originarios" o llamados también "ingresos ordinarios", que son los tributos que deben satisfacer quienes resulten incluidos en la hipótesis legal. 
De ello surge la ciencia de las finanzas y ciencia fiscal. Ésta es el conjunto de reglas y principios que determinan la manera de constituir, administrar e invertir el patrimonio público. En la constitución del patrimonio público, la ciencia fiscal estudia la manera de formarlo, analizando detalladamente las distintas fuentes de ingreso que componen el tesoro o el erario, así de aquellos que emanan de la comunidad misma, como de los que provienen del tesoro de los particulares. En la administración del expresado patrimonio, la ciencia fiscal estudia la organización que debe dársela al manejo y recaudación de los dineros públicos, señalando las normas para que aquellas funciones se desempeñen con la mayor eficacia, equidad y economía. Y por lo último, en la inversión de los fondos públicos, dicha ciencia establece los principios fundamentales de los gastos comunes, a fin de que aquellos se decreten y se realicen en forma tal y en cuantía tal que correspondan debidamente a la satisfacción de las necesidades colectivas dentro de las necesidades económicas de la respectiva entidad políti$\mathrm{ca}^{5}$

El Derecho disciplina esta facultad estatal con el objeto de impedir - esencialmente a través de normas constitucionales - la confiscación o exacción arbitraria, mediante la aplicación de determinados principios que tienden a garantizar lo que, de manera sintética, podría denominarse justicia en la imposición. ${ }^{6}$

Los principios hegemónicos del Derecho Tributario son la garantía de que gozan los contribuyentes frente al Estado, cuyo poder tributario o capacidad jurídica para crear tributos se encuentra limitada precisamente por estos principios. ${ }^{7}$

Una de tales garantías está constituida por el principio de legalidad, (Art. 74 de la Constitución Política 1993 “... la creación, modificación o derogación de un tributo sólo puede efectuarse por ley"), y constituye la piedra angular del Derecho Tributario. El mismo puede resumirse señalando que los tributos sólo deben ser establecidos con la aceptación de las personas que resulten obligadas a satisfacerlos. En el mundo contemporáneo ello implica que los tributos sólo pueden ser creados por el Poder Legislativo, ya que sus miembros son elegidos por el pueblo y representan, teóricamente, la aceptación de aquél. ${ }^{8}$

"El principio de legalidad significa que la ley que establece el tributo debe definir cuáles son los elementos y supuestos de la obligación tributaria, esto es, los hechos imponibles, los sujetos pasivos de la obligación que va a nacer, así como el objeto y la cantidad de las prestaciones, por lo que todos esos elementos no deben quedar al arbitrio o discreción de la autoridad administrativa. La ley debe establecer también las exenciones".

La parte final del segundo párrafo de la Constitución Política trata de los principios en materia tributaria como:

La reserva de la ley, quiere decir que sólo por normas con rango de ley pueden crear, modificar, suprimir o exonerar tributos. Nadie más puede arrogarse esa función. La igualdad, que debe entenderse como la aplicación de los impuestos sin privilegios, a todos aquellos que deben pagarlos, según se establezca en la ley. Respeto a los derechos fundamentales de la persona. La no confiscatoriedad, que significa que el impuesto pagado sobre un bien no puede equivaler a todo el precio del bien, o a una parte apreciable de su valor. Técnicamente hablando, confiscar es quitar la propiedad de un bien sin pagar un precio a cambio. Aquí, obviamente, se utiliza el término en sentido analógico, no estricto. ${ }^{10}$

Sin embargo, observamos que desde algún tiempo de manera más o menos imper- 
ceptible se ha venido produciendo en el Perú una variación en el "sentimiento" jurídico que permite trazar una curva descendente en la aplicación del principio de legalidad, hasta hacerlo desaparecer en unos casos y volverlos irreconocibles en otros. Esta tendencia ha conducido al paulatino desplazamiento del Congreso del campo tributario que era, antes, una suerte de área privativa y exclusiva.

La exigencia constitucional derivada del principio de legalidad tributaria según el cual, la ley debe establecer los elementos esenciales o nucleares del tributo es un fundamento irrebatible para que se pueda tachar de inconstitucional a todas aquellas normas que pretendan introducir deslegalizaciones en materias cubiertas por la reserva legal. Se infringe la Constitución cuando la ley deja librado al criterio discrecional del Gobierno la fijación de los elementos estructurales del tributo.

Sin embargo, debemos considerar que si bien es cierto que por intereses especiales y particulares no se ha incluido en la Constitución Política de 1993 otros principios tributarios importantes como el de la Capacidad Contributiva, Neutralidad y Economía en la Recaudación estos, se debe internalizar dentro del marco jurídico tributario.

CAPACIDAD CONTRIBUTIVA.- La tributación debe adecuarse a la realidad económica del contribuyente, en ese sentido no todos pagan los mismos tributos, sino será mayor en quienes tengan una superior capacidad económica y no al contrario como se viene aplicando en los momentos actuales. ${ }^{11}$

NEUTRALIDAD.- Por este principio se entiende que los impuestos no deben interferir con el logro de óptimos niveles de vida. La estructura impositiva debe concebirse de tal forma que elimine toda interferencia con el logro de una óptima distribución y uso de los recursos y, de ser posible, que contribuya a ese objetivo. Por tanto, el fin último de todo sistema tributario es una reducción al mínimo de sus efectos adversos. Debe coadyuvar y no ser obstáculo para el desarrollo económico.

ECONOMÍA EN LA RECAUDACIÓN.Principio por el que se requiere que los tributos se establezcan en forma tal que lleven los costos efectivos de recaudación a un mínimo, en función de los recursos necesarios para percibir los impuestos, así como también en función de los inconvenientes directos causados a los contribuyentes por el pago de impuestos.

Estos principios deben reconsiderarse e incluirlos como, rectores y mecanismos de protección contra la discrecionalidad arbitraria de los gobernantes de turno.

El reglamento tributario ostenta un carácter ejecutivo, es decir, se limita a completar cuestiones de detalle o adoptar las medidas estrictamente necesarias para la aplicación de la ley sin que se pueda añadir a los preceptos de ésta otros nuevos no justificados por dicha necesidad.

Es obvio que no puede suplantar lo dispuesto por la ley, ni introducir desarrollos normativos contradictorios con las disposiciones legales, ni invadir el contenido propio de la ley en los supuestos de las materias reservadas constitucionalmente a la ley.

Es menester estar vigilantes a fin de impedir que un Poder Ejecutivo desprovisto del recurso a la legislación de urgencia se vea tentado de promover la progresiva degradación del cargo de la ley de la materia tributaria por el fácil expediente de incorporar el régimen legal de cada tributo disposiciones que otorgue facultades al gobierno o a la administración tributaria para regular o intro- 
ducir modificaciones a través de normas de rango inferior a la ley, en aspectos sustanciales de los tributos cubiertos por el principio constitucional de reserva de la ley.

El planteamiento de Villegas, de acuerdo con el cual los sistemas tributarios varían de país a país, es acertado porque sus condiciones estructurales, afianzadas a lo largo de la historia, inciden en todas las expresiones jurídicas que le son propias y, entre ellas, naturalmente la fiscal.

El curso de la historia incide en el sistema tributario porque si el ordenamiento en general es dinámico y en manera alguna puede quedarse a la zaga de los acontecimientos, no a otra conclusión distinta puede arribarse en materia tributaria. Mas esa dependencia de los tributos de las condiciones imperantes en el momento de que se trate, no es suficiente para definir la verdadera conformación sistemática del conjunto porque, como lo destacan Tarantino y Villegas, sin unos fines precisos hacia los cuales se oriente el ordenamiento fiscal no sería viable afirmar que hay un verdadero sistema sino un simple régimen tributario. ${ }^{12}$

Para la racionalidad del sistema tributario, es indispensable que la realidad jurídica alrededor de la cual se consolide la obligación tributaria sea caracterizada por la más absoluta certeza, de forma tal que los vacíos normativos no den lugar a inequidades ni dejen a los administrados en medio de la duda y la inseguridad. Desde la perspectiva de la administración, el ordenamiento jurídico tributario debe evitar que los errores o imprecisiones en las normas conlleven canales de evasión y de fraude que desquicien los objetivos perseguidos con el conjunto armónico de los tributos. Los hechos generadores de la obligación tributaria deben ser descritos en una forma simple, diáfana y amplia. Las descripciones excesivas y la inclusión de numerosas hipótesis de incidencia logran el efecto contrario de lo que en apariencia pretenden. ${ }^{13}$

\section{SINOPSIS DE CONCEPTOS BÁSICOS APLICABLES}

\section{POLÍTICA ECONÓMICA}

Conjunto de medidas que da un gobierno en el ámbito económico y que están dirigidas a cumplir sus funciones de acuerdo a su óptica y pensamiento.

A pesar de que la Política Económica comprende un conjunto significativo de medidas, estas concuerdan entre sí y se orientan hacia el logro de sus determinadas finalidades. $^{14}$

En el mundo actual, los objetivos económicos varían de acuerdo al pensamiento del grupo humano que está gobernando en una determinada Nación y en un determinado periodo de tiempo.

\section{POLÍTICA FISCAL}

Conjunto de orientaciones, pensamientos y decisiones que adopta el Gobierno de un Estado para conseguir sus objetivos económicos y sociales a través de medidas vinculadas al ingreso y gasto público.

Fiscal viene de la palabra "Fisco" que significa "Tesoro del Estado", tesoro público que pertenece a todos.

La Política Fiscal es el procedimiento que sigue el Sector Público relacionado con sus decisiones sobre el gasto, tributos y endeudamiento.

Esta política tiene como objetivo facilitar e incentivar el buen desempeño de la economía nacional para lograr niveles aceptables o sobresalientes de crecimiento, inflación y desempleo, entre otras variables, igualmente, busca evitar fluctuaciones en la economía (Ciclos Económicos). ${ }^{15}$ 


\section{GASTO PÚBLICO}

Es la definición de las inversiones de recursos estatales. Son los desembolsos de dinero que realiza el Estado, conforme a Ley para cumplir los fines que no son otros que la satisfacción de las necesidades públicas.

Se define como el empleo de medios económicos realizados por las instituciones públicas. ${ }^{16}$

\section{ACTIVIDAD FINANCIERA Y SU INTE- GRACIÓN}

Esta debe responder a razonamientos técnicos y a límites muy precisos:

Si rebasan indiscriminadamente (préstamos excesivos) agotan la "capacidad de endeudamiento"

Si se traduce en cargas tributarias "ciegas" saturan la "presión tributaria" o capacidad de soportar del contribuyente. Situaciones que provocan desequilibrio y problemas muy serios a nivel presupuestario y conducen a otro tipo de problemas muy complejos como la inflación.

\section{Integración:}

Actividad Financiera: Objetivo fundamental posibilita que el Estado cumpla con sus fines.

Aplicación de Políticas: Económicas, Sociales, Técnicas. Aspecto Jurídico: Derecho Financiero, estudia normas jurídicas sobre leyes que determinan distribución de "Cargas" públicas con el objeto de indicar su interpretación "exacta".

\section{DEFINICIÓN DEL TRIBUTO}

Es la obligación generalmente dineraria generada por un hecho económico que se encuentra gravado según Ley. Son las prestaciones (entregas) en dinero y/o en especie que el Estado, en ejercicio de su poder de impe- rio, exige con el objeto de obtener recursos para el cumplimiento de sus fines (Art. 13 modelo Código Tributario para América Latina) Programa de Tributación OEA/BID).

\section{NACIMIENTO, RELACIÓN O VÍNCU- LO ENTRE LA PERSONA, EL ESTADO Y NORMA TRIBUTARIA}

Tributo. Nace por la realización hecho económico gravado (generador de Tributos). El supuesto. Tributo establecido sólo por Ley (Principio de Legalidad- Reserva de la Ley).

La consecuencia, efecto. Relación (vínculo jurídico tributario.) Nexo lógico jurídico. Vínculo entre el supuesto y la consecuencia o el efecto.

\section{NATURALEZA JURÍDICA DE LA OBLI- GACIÓN TRIBUTARIA}

EL ESTADO: (Acreedor tributario). Derecho a percibir y exigir inclusive coactivamente (imposición) la entrega del Tributo.

EL CONTRIBUYENTE: (sostenedor del Estado) (Deudor tributario). como deber/ obligación de entregar el tributo.

\section{APLICACIÓN NORMATIVA EN EL PAÍS \\ Contenido sustancial de la norma tributaria. Significa conocer: donde, desde cuándo y a quienes se aplican las normas.}

\section{TÉCNICA Y ADMINISTRACIÓN FIS- CAL}

Conjunto ordenado racional y armónico de principios, normas o reglas, concordante entre sí que contribuyen a un objetivo predeterminado.

Conjunto de tributos vigentes en un país o época (tiempo) determinado el análisis o estudio del conjunto debe hacerse como un todo y no aisladamente ya que los efectos que 
produzcan los tributos pueden equilibrarse y corregirse entre sí.

Conjunto de normas e instituciones que sirven de instrumento para la transferencia de recursos de las personas al Estado con el objeto de sufragar el gasto público. ${ }^{17}$

\section{RÉGIMEN TRIBUTARIO}

Reglas que imponen tributos sin armonía, sin orden o sin investigación sobre la capacidad contributiva, con el solo fin de lograr mayores ingresos para el Tesoro Público (Fisco).

Imposición de reglas o seguimientos inorgánicos, sin orden y sin investigación de causas, con el sólo propósito de lograr más fondos.

\section{SISTEMA TRIBUTARIO}

\section{Sistema Tributario Histórico (Evolución Histórica)}

Cuando la "armonía" entre los objetivos por medio de la Tributación y medios empleados se producen por espontaneidad de la Evolución Histórica. (Repertorio de Tributos surgidos de necesidades pecuniarias estatales).

Realmente no existe "armonía" de los tributos.

\section{SISTEMA TRIBUTARIO RACIONAL}

\section{Aspecto financiero}

Un sistema tributario racional es bueno cuando:

Los tributos son productivos. Los resultados son suficientes en épocas normales o anormales. No debe ser un sistema vulnerable a circunstancias que la Administración del Estado no puede manejar.

\section{Aspecto económico}

Un sistema tributario racional y bueno no debe atentar contra la producción nacional. Debe ser concebido como un instrumento de política económica de incentivo a la producción nacional.

\section{Aspecto social}

Un sistema tributario racional bueno establece:

Un sacrificio mínimo en el contribuyente. La carga tributaria debe ser distributiva de acuerdo con la capacidad contributiva (Paga más quien tiene más rentas).

Un sistema tributario injusto lleva inevitablemente a la evasión tributaria. Debe existir armonía entre la recaudación tributaria y la redistribución vía gasto público social.

\section{Aspecto administrativo}

Un sistema tributario racional bueno debe ser:

Simple y entendible. Debe brindar facilidades para el pago y/o cumplimiento de las obligaciones tributarias. Debe sacrificar el tecnicismo y permitir la claridad. Debe ser eficiente y a bajo costo.

\section{POLÍTICA TRIBUTARIA-FISCAL}

Disciplina que determina, una vez acordado el principio de recaudación por ingreso fiscal, las características generales del tributo en función a la información económica y psicológica de la población. Estas tienen íntima conexión con la política presupuestaria y con la técnica fiscal.

\section{SISTEMA TRIBUTARIO IDEAL}

Aplicación Principio de Equidad - Capacidad de Pago. Paga más quien tiene mayor capacidad económica. 
Partes de este principio: Equidad horizontal y equidad vertical.

\section{Equidad horizontal:}

Se denomina al objetivo de buscar que las personas con recursos iguales paguen montos por tributos iguales "tratar igual a los iguales".

Ejemplo: Estudio Gastos deducibles para determinar la Renta Imponible en base a la capacidad de pago.

\section{Equidad vertical:}

Se denomina al objetivo de buscar que las personas con más ingresos paguen mayores montos por tributos "tratar desigual a los desiguales" o "pudientes deben pagar más que los no pudientes".

Esta equidad está vinculada íntimamente con el concepto de progresividad (Escalas progresivas).

\section{CONCORDANCIA ENTRE TRIBUTOS}

Un sistema tributario racional debe mostrar con simplicidad tributos equitativos concordados y armonizados para su ejecución, aplicación y cumplimiento por los contribuyentes. Debe lograr:

- La presión tributaria adecuada para producir efectos reales en la economía.

- Tributos productivos (que se puedan pagar en cualquier época del año)

- Incentivar a la producción nacional (instrumento de política económica)

- Un buen y sostenido apoyo administrativo (responsabilidad básica del administrador de un Estado: Gobierno, para recaudar y otorgar seguridad jurídica)

- Actualización y desarrollo eficiente

- Profundidad y rapidez con calidad, a menor costo

- Fiscalización: Factores objetividad, formalidad, prescripción y riesgo.
Con la sinopsis arriba mencionada, ahora podemos inferir la situación de nuestro Sistema Tributario vigente:

\section{PRINCIPALES CARACTERÍSTICAS DEL ACTUAL SISTEMA TRIBUTARIO PERUANO}

La carga tributaria en el Perú tiene un nivel medio en el contexto latinoamericano, pero baja respecto al resto de regiones y de las necesidades básicas del país; esto se debe en particular a una importante evasión, cierta falta de capacidad de la administración tributaria y una frágil gobernabilidad.

- El Perú tiene una fuerte dependencia de los impuestos indirectos y un limitado menú de impuestos al capital y a la renta, lo que eleva su inestabilidad y vulnerabilidad ante los ciclos económicos y crisis externas.

- El limitado impacto de los programas sociales no permite contrarrestar las ineficiencias y los efectos negativos del sistema tributario sobre la distribución de ingresos

- El conflicto de objetivo; se trata de un conflicto de objetivos a distintos niveles que se superponen entre sí, como por ejemplo, entre funciones básicas del Estado, entre intereses políticos y aspectos técnicos, entre presiones de corto plazo y metas de mediano plazo.

- La brecha entre el sistema tributario legal $y$ el efectivo, el gobierno ejerce control sobre el sistema tributario legal pero tiene poca influencia en el sistema efectivo y entre ambos la brecha es significativa.

- La débil fiscalidad radica en la debilidad del pacto social entre el Estado y la sociedad.

- El factor político juega un rol central y hasta preponderante por sobre lo técnico; 
- Los objetivos de recaudación de corto plazo han caracterizado a las reformas y modificaciones del sistema tributario.

- Al sistema tributario se le ha venido exigiendo lograr objetivos múltiples de manera simultánea.

- Bajo objetivos considerados progresivos y equitativos, se han introducido mecanismos que han erosionado el sistema generando efectos contrarios a los deseados.

- Existe un divorcio macro-micro que no ha permitido una consistencia entre el crecimiento económico y la reducción de la pobreza.

- El diseño del sistema tributario tiene en esencia los principios básicos deseados por un sistema tributario, sin embargo, se ha ido deteriorando y perforando progresivamente durante los últimos años.

- Si bien la administración tributaria ha logrado avances importantes, la eficiencia y la eficacia de la recaudación deben seguir mejorando

- No existe una legitimación ni credibilidad en el sistema tributario en la medida que, por el lado del pago de impuestos, se perciben altos grados de inequidad horizontal y opacidad de los mecanismos implementados $y$, por el lado del destino de los recursos, no se percibe una adecuada atención a las necesidades de la población, tanto en términos de cobertura como de calidad. ${ }^{18}$

- No existe en el país un sistema tributario estable. Constantemente se realizan cambios en el sistema impositivo bajo la óptica estatal y considerando únicamente las necesidades de caja fiscal. Lo que existe son regímenes tributarios con normas cortoplacistas para recaudar más.

- Tampoco existe una filosofía tributaria definida hacia la imposición directa o indirecta, que sirva de soporte al sistema tributario vigente. Esto impide planificar al mediano y largo plazos tanto al fisco como a la empresa privada.

- Se usa indiscriminadamente la "potestad tributaria delegada”, encargándose a la propia administración la labor legislativa, haciéndola siempre con tendencia "Pro Fisco" y simple afán recaudatorio.

- La política tributaria está basada en el incremento de tasas, limitación de gastos, impuestos adelantados, impuestos temporales y excesivas formalidades carentes de proyección en el mediano y largo plazo, porque se sustenta en mecanismos coyunturales para recaudar y gastar ahora, sin visión de futuro.

- La legislación vigente tiene excesos formalistas que no son promotoras del desarrollo, que se convierten en sobrecostos y en barreras burocráticas que afectan a los que siempre soportan la carga fiscal.

- Las disposiciones tributarias no son claras, precisas ni de fácil comprensión para los contribuyentes, en especial para los micro y pequeños empresarios que no cuentan con asesores ni especialistas en tan complicada materia, quienes perciben que las normas tributarias pareciera que los dictara el "hombre araña" porque todo se configura como una telaraña tributaria.

- La ley tributaria debe ser fruto del debate parlamentario, donde pueden analizarse las diversas tendencias para gravar o no los hechos imponibles, y se le agrega el conocimiento especializado y el ingrediente político, entendido éste en su connotación de metas y planes de desarrollo del país. ${ }^{19}$

PRINCIPALES INEQUIDADES DEL SISTEMA TRIBUTARIO PERUANO

Vol. 16(1) 2009 | QUIPURAMAYoc / 181 
Es necesario entender la equidad en el sistema tributario no como un objetivo central sino como una variable de diseño estrechamente vinculada y complementaria a los principios esenciales de simplicidad, neutralidad y eficiencia.

La equidad es necesaria, pero su correcta implementación es decisiva. Los objetivos de redistribución de ingresos se beneficiarán en la medida que se tenga la capacidad de elevar la recaudación y favorecer, a la vez, la progresividad del sistema sin causar mayores distorsiones económicas. ${ }^{20}$

Entre las principales inequidades del sistema tributario destacan:

- En el impuesto a la renta a las personas naturales, la progresividad se ha expresado en una cada vez más alta tasa marginal máxima y en un mínimo nivel de ingreso deducible. Tasas marginales muy elevadas promueven la evasión.

- En el impuesto general a las ventas, bajo un enfoque de seudoequidad, se han dictado leyes exonerando del pago del IGV a diferentes productos $\mathrm{y}$ regiones $\mathrm{y}$ otorgando créditos fiscales especiales, sin mayores evaluaciones costo-beneficio de lo que esto representa en términos de recaudación.

- Incidencia regresiva de la tributación indirecta que tiene el IGV respecto de la distribución del ingreso. Pese a que el $10 \%$ de la población de mayores ingresos tiene un nivel promedio de ingresos por familia 21 veces mayor que el de menores ingresos, el esfuerzo tributario de los más pobres es cerca del doble del de los más ricos, lo que muestra el grado de inequidad que supone la aplicación de este tipo de impuestos.

- El impuesto a la renta es, por naturaleza, progresivo y podría llegar a contrarrestar los efectos regresivos de los impuestos indirectos. Sin embargo, los impuestos indirectos tienen un peso mucho más significativos dentro de la estructura tributaria y la magnitud de los efectos positivos de la tributación directa está significativamente disminuido por la proliferación de gastos tributarios, evasión y elusión. Además, como el 53\% de la población vive en situación de pobreza, los contribuyentes exentos del impuesto a la renta son la mayoría y debido a la concentración de la riqueza se da un bajo nivel de recaudación dado que los contribuyentes de mayores recursos tienen más alternativas para evitar el pago del impuesto.

- La proliferación de cambios legales, llegando a establecer tantos regímenes especiales y exenciones que perfilaron la estructura tributaria hacia una complejidad e inequidad afectaron precisamente la suficiencia, si tenemos en cuenta que los incentivos y exoneraciones tributarias se sobreponen y combinan, de modo que algunos agentes pueden tener diferentes tipos de beneficios derivados de tratamientos preferencial es proveniente de diversos impuestos (según tipos de impuestos, actividades o regiones, por ejemplo), podemos concluir que el panorama de incentivos o exoneraciones tributarias es vasto y complejo, propiciando ello mayores oportunidades de evasión y elusión, por ello. para combatir eficazmente este aspecto se debe ampliar la base tributaria más que elevar las tasas de impuestos y por otra parte, combatir eficazmente la evasión tributaria.

- Los convenios de estabilidad y los regímenes especiales acentúan la inequidad horizontal, estos contratos "congelan" el régimen tributario de estas empresas y brindan beneficios de libre remesa de 
utilidades, tipo de cambio preferencial, etc., durante 10 años, en la mayoría de los casos.

- Existe una suerte de analogía entre los regímenes especiales de tributación y las exenciones de impuestos, ya que ambos pretenden que determinados contribuyentes se eximan de determinadas obligaciones, las propias de un sistema de tributación de tipo general por una parte y la carga tributaria por otra.

\section{PROPUESTA PARA UNA REFORMA TRIBUTARIA INTEGRAL CON EQUIDAD}

El reto fundamental de la Reforma Tributaria Integral con Equidad reside en la necesaria ampliación de la base tributaria, la formalización de la economía y la reforma del Estado, de forma tal que se incremente el nivel de presión tributaria a $14 \%$ en el corto plazo y a $16 \%$ en el mediano. Es imprescindible modernizar, simplificar y dar mayor progresividad al sistema, ampliando la base impositiva y reduciendo la informalidad y la evasión.

Es necesario tener en cuenta que en el Perú existe un problema de credibilidad de la política tributaria, porque lo relevante es el establecimiento de reglas de juego claras y estables que permitan el desarrollo de la actividad económica, y no los recursos en sí mismos. Nada se gana con arbitrar recursos si no se recupera la credibilidad. Es al revés, hay que recuperar la credibilidad para tener acceso a recursos y ello es posible con reformas sustanciales, coherentes y complementarias, tanto en el ámbito de los ingresos como de los egresos.

El proceso hacia una reforma tributaria integral con equidad, puede concebirse considerando las etapas ineludibles como:

"Limpiar" gradualmente el Sistema Tri- butario actual, iniciar un proceso de diálogo abierto en temas tributarios y bien informados, involucrando a todos los actores (sector público, sector privado y sociedad civil), no debatiendo propuestas específicas ni tratando de lograr acuerdos sobre ellas, sino discutiendo los grandes temas tributarios como la eficiencia, simplicidad, equidad, informalidad, etc., con el fin de ir sentando las bases para la elaboración de un pacto fiscal para finalmente sentar las bases de la gobernabilidad del sistema tributario integral con equidad sustentada en un pacto fiscal que cuente con el funcionamiento de un conjunto de mecanismos que garantice el cumplimiento de dicho pacto social.

Lograr y consolidar un pacto fiscal implica cumplir requisitos y compromisos claves por parte de los diferentes sectores e intereses público y privado, económico, social y político con miras a consolidar la modernización del sector público y promover el bienestar social y el desarrollo económico. ${ }^{21}$

\section{¿Qué es un Pacto Fiscal?}

El pacto fiscal es un acuerdo sociopolítico básico que legitima el papel del Estado y el ámbito de alcance de las responsabilidades gubernamentales en la esfera económica y social.

El pacto fiscal debe tener objetivos de mediano plazo. Su implementación no debe corresponder a un solo periodo de gobierno, sino al menos a tres gobiernos sucesivos.

Cinco deben ser los objetivos de un pacto fiscal:

1. Consolidar la sostenibilidad fiscal, el mejor indicador de la sostenibilidad fiscal es el ratio deuda pública/PBI.

2. Promover la equidad, la política fiscal no debe reducirse a que las "cuentas cuadren”. Para lograr la equidad, tanto la política tributaria como el gasto pú- 
blico desempeñan un papel importante. Respecto a la política tributaria, si bien debiéramos concentrarnos en su simplicidad, para asegurar recaudar lo máximo posible, ello no debiera conducirnos a "renunciar" a una importante recaudación del impuesto a la renta, el impuesto equitativo por excelencia. Respecto al gasto público, es imprescindible su priorización en los programas de gasto que mayor impacto tienen en el crecimiento económico (infraestructura) y en su impacto en los más pobres (educación primaria y salud preventiva)

3. Mejorar la calidad del gasto público, los ciudadanos demandan mejores servicios, ellos no están dispuestos a contribuir con el pago de sus tributos si a cambio no se observa educación pública de calidad, servicios de salud pública de calidad y servicios de seguridad ciudadana de calidad.

4. Mejorar la transparencia de la gestión pública, la falta de transparencia es fuente de corrupción. La transparencia de la gestión no debe limitarse a la diseminación de información a través de diversos canales, aspectos en el que se han logrado avances con los portales de Internet. Asimismo, debiera reducirse la utilización de instrumentos fiscales como las exoneraciones y otros beneficios tributarios, han demostrado que son ineficaces e ineficientes para promover el desarrollo de regiones o sectores económicos específicos.

5. Fortalecer las instituciones, un pacto fiscal requiere de instituciones sólidas, se necesita fortalecer a las instituciones más débiles, en este caso a los gobiernos locales y regionales. No se debe descuidar el reforzamiento de la autonomía de la Sunat y del Tribunal Fiscal. ${ }^{22}$

\section{CONCLUSIONES}

1. No existe en el país un sistema tributario estable. Constantemente se realizan cambios en el sistema impositivo bajo la óptica estatal y considerando únicamente las necesidades de caja fiscal. Lo que existe son regímenes tributarios con normas cortoplacistas para recaudar más.

2-. El Perú tiene una fuerte dependencia de los impuestos indirectos y un limitado menú de impuestos al capital y a la renta, lo que eleva su inestabilidad y vulnerabilidad ante los ciclos económicos y crisis externas.

3. Existe una brecha entre el sistema tributario legal y el efectivo, el gobierno ejerce control sobre el sistema tributario legal pero tiene poca influencia en el sistema efectivo y entre ambos la brecha es significativa.

4. El factor político juega un rol central y hasta preponderante por sobre lo técnico; los objetivos de recaudación de corto plazo han caracterizado a las reformas y modificaciones del sistema tributario.

5. Bajo objetivos considerados progresivos y equitativos, se han introducido mecanismos que han erosionado el sistema generando efectos contrarios a los deseados.

6. No existe una legitimación ni credibilidad en el sistema tributario en la medida que, por el lado del pago de impuestos, se perciben altos grados de inequidad horizontal y opacidad de los mecanismos implementados y, por el lado del destino de los recursos, no se percibe una adecuada atención a las necesidades de la población, tanto en términos de cobertura como de calidad.

7. Se usa indiscriminadamente la "potestad tributaria delegada”, encargándose a la 
propia administración la labor legislativa, haciéndola siempre con tendencia "Pro Fisco" y simple afán recaudatorio.

8. La política tributaria está basada en el incremento de tasas, limitación de gastos, impuestos adelantados, impuestos temporales y excesivas formalidades carentes de proyección en el mediano y largo plazo, porque se sustenta en mecanismos coyunturales para recaudar y gastar ahora, sin visión de futuro.

9. La legislación vigente tiene excesos formalistas que no son promotoras del desarrollo, que se convierten en sobrecostos y en barreras burocráticas que afectan a los que siempre soportan la carga fiscal.

10. Las disposiciones tributarias no son claras ni precisas ni de fácil comprensión para los contribuyentes, en especial para los micro y pequeños empresarios que no cuentan con asesores ni especialistas en tan complicada materia, quienes perciben que las normas tributarias pareciera que los dictara el "hombre araña" porque parece que todo pareciera una telaraña tributaria.

11.Tenemos la imperiosa necesidad de abordar los criterios de equidad y gobernabilidad en la evaluación del sistema tributario peruano y su reforma en una perspectiva de largo plazo y en el contexto más amplio de la reforma del Estado, a fin de propender la visión: "Hacia la eliminación de inequidades en el sistema tributario... Propuestas para una reforma tributaria integral con equidad”.

\section{ALGUNAS RECOMENDACIONES}

\section{El sistema tributario y el desarrollo económico \\ El sistema tributario propuesto deberá}

inscribirse dentro de un plan de desarrollo económico a largo plazo. De lo contrario, la tributación deviene en factor que traba el desarrollo en lugar de propiciarlo. Constantemente, nuestras instituciones reclaman que se utilice al tributo como factor de promoción y desarrollo y no como simple esquema de las finanzas públicas, con mero sentido recaudatorio. El tributo se usa incluso como elemento corrector de los ciclos económicos, especialmente para reactivar economías que atraviesan problemas coyunturales de tipo recesivo, como es nuestro caso.

\section{Lineamientos para una reforma tribu-} taria

- No incrementar tributos, para el contribuyente formal la presión tributaria es $30 \%$, considerando que el $60 \%$ de la economía corresponde al sector informal que no paga impuestos formales.

- Sancionar la evasión, el código y las leyes tributarias deben ser drásticas y ejemplares para con el evasor, el falsificador, el contrabandista, el informal $y$ en general con todo el que se desenvuelva al margen de la ley.

- Simplificación administrativa, deben eliminarse todas las barreras y trabas burocráticas injustificadas e irracionales que limiten el acceso o permanencia de las empresas en el mercado.

- Tributos antitécnicos, deben eliminarse los tributos antitécnicos, tales como el ITAN, ITF, se debe eliminar disposiciones pro fiscalistas como las percepciones del IGV, que obligan a pagar impuestos que el contribuyente no debe. 
- Formalismos, la reforma tributaria debe desterrar los formalismos, que muchas veces prevalecen sobre las cuestiones esenciales o de fondo, haciendo intolerable el sistema impositivo par el contribuyente formal. El incumplimiento de formalidades deben sancionarse con multas y no con el desconocimiento del derecho de deducir gasto, costo o crédito fiscal.

- Tributo único para MYPE, Mejorar el RUS o establecer un régimen tributario promocional para las MYPE; las que deben estar facultadas a emitir boletas de venta que permitan deducir el 100\% del gasto.

- Exoneraciones tributarias, racionalizar y posteriormente eliminar las exoneraciones tributarias (actualmente estarían bordeando el $10 \%$ del presupuesto nacional) en lugar de las exoneraciones podrían, en casos especiales, rebajarse las tasas impositivas (ejemplo: sector agrario).

\section{Simplificación del sistema tributario}

Un sistema tributario complejo atenta contra los objetivos principales de la tributación vale decir, desmotiva al contribuyente, encarece el costo administrativo y minimiza la recaudación. Por lo tanto, es preciso implantar un sistema de tributación simple y equitativa, para lo cual se requiere, entre otras cosas:

Que las disposiciones tributarias observen rigurosamente los principios tributarios que la Constitución prescribe (reserva de la ley, igualdad, respeto de los derechos fundamentales de la persona y que ningún tributo tiene efecto confiscatorio)

Reducir el número de los tributos, en especial los municipales, de tal manera que el sistema tributario descanse en el menor número posible de impuestos y contribuciones.

Establecer reglas fáciles de aplicar, de modo que el cumplimiento de las normas tributarias no signifique una carga onerosa de por sí para los contribuyentes.

Centralizar la administración de los impuestos en una sola entidad del Estado que ejerza una acción fiscalizadora eficaz, lo cual requiere de cuerpos especializados que. Al mismo tiempo que mantienen un control efectivo, permanente y actualizado del cumplimiento de los contribuyentes, utilicen medios de información a tono con los avances de la tecnología de la información.

Reiteramos la necesidad de perfeccionar el sistema impositivo del país en forma expeditiva y coherente con el modelo económico en ejecución, uno de cuyos basamentos debe ser precisamente la claridad, simplicidad y estabilidad de las normas legales y que además deben ser técnicamente elaboradas para que la tributación sea en efecto instrumento promotor del desarrollo.

\section{La ampliación de la base tributaria}

La ampliación de la base tributaria depende mucho de la simplificación de la tributación, de la distribución equitativa de la carga tributaria, de la fiscalización efectiva y de la eliminación de las exoneraciones, las cuales de persistir, sólo deberían establecerse para determinados bienes o transacciones claramente especificados en la ley.

Reiteramos que la carga tributaria, debe recaer en todos los contribuyentes; pues todos estamos obligados a pagar nuestros impuestos en función de la capacidad contributiva de cada quien. En tal sentido, la administración tributaria no sólo 
debe fiscalizar al contribuyente cautivo sino al informal que no paga los impuestos y que además, genera competencia desleal a la empresa legalmente establecida.

La ampliación de la base tributaria no puede reposar sólo en la base "cualitativa" sino en la base "cuantitativa". Sabemos que la administración de los impuestos es cara, pero con el avance tecnológico y la simplificación efectiva de la ley tributaria, aunado a gran imaginación gerencial para usar el tributo como factor de promoción del desarrollo, podrán incorporarse a miles de contribuyentes potenciales. Muchas veces la oscuridad de la ley la complejidad de los formularios y requisitos burocráticos desalientan el pago de tributos y en forma indirecta, propician el incumplimiento de la ley. $\mathrm{Al}$ igual que las tasas muy altas.

\section{La concepción de las normas tributa-} rias

La concepción y redacción de las normas tributarias debería considerar la participación de especialistas en diversos campos profesionales, que tienen relación con la ciencia tributaria. La elaboración de la ley tributaria debe recibir aportes de abogados, contadores, economistas, administradores de empresas, penalistas, tributaristas, empresarios y docentes; en fin; es una tarea multidisciplinaria en una realidad tan compleja como la que vivimos; no puede ser manejada sólo por técnicos fiscales. Creemos que deben participar todos los que tienen algo que aportar para lograr que la norma general sea completa y no se busque eludirla o evadirla con dolo. Debe prevalecer en esta tarea el alto interés del país.

Las normas, antes de ser aprobadas, de- ben ser difundidas profusamente, dando oportunidad a que la ciudadanía tenga los elementos de juicio necesarios para plantear sus puntos de vista de modo que, cuando sean sancionadas por el Poder Legislativo y promulgadas por el Poder Ejecutivo, todos los sectores de la población hayan sido debidamente informados de sus efectos.

\section{REFERENCIAS BIBLIOGRÁFICAS}

1. Mauricio A. Plazas Vega. El liberalismo y la Teoría de los Tributos. p. 189

2. Mauricio A. Plazas Vega. El liberalismo y la Teoría de los Tributos. p. 200

3. Mauricio A. Plazas Vega. El liberalismo y la Teoría de los Tributos. p. 208

4. Mauricio A. Plazas Vega. El liberalismo y la Teoría de los Tributos. p. 189

5. Humberto Medrano. Iust et Veritas No. 10.1995

6. Juan Velásquez Calderón. Derecho Tributario Moderno p. 18

7. Juan Velásquez Calderón. Derecho Tributario Moderno p. 20

8. Humberto Medrano. Iust et Veritas No. 10. 1995

9. La Garza, Sergio. Derecho Financiero Mexicano. Editorial Porrúa, 1983, páginas 251 y 252

10. Marcial Rubio Correa, Para conocer la Constitución de 1993 
11. Adolfo Valencia Gutiérrez, Ponencia Hacia un Sistema Tributario Moderno... no temporal, Tributa 95,

12. Mauricio A. Plazas Vega. El liberalismo y la Teoría de los Tributos. p. 259

13. Mauricio A. Plazas Vega. El liberalismo y la Teoría de los Tributos. p. 261

14. Pedro M. Ramírez Rossel, Exposición Curso Auditoria Tributaria, UIGV

15. Pedro M. Ramírez Rossel, Exposición Curso Auditoria Tributaria, UIGV
16. Pedro M. Ramírez Rossel, Exposición Curso Auditoria Tributaria, UIGV

17. Pedro M. Ramírez Rossel, Exposición Curso Auditoria Tributaria, UIGV

18. Pedro M. Ramírez Rossel, Exposición Curso Auditoria Tributaria, UIGV

19. Revista El Contador Público, CCPL, Enero-Febrero 2005, pág. 7

20. Reforma integral del sistema Tributario, Mayo 2005 Cámara de comercio de Lima CCL 